\title{
PREPARATION OF NOVOLACS USING PHENOLIC RICH COMPONENTS AS PARTIAL SUBSTITUTE OF PHENOL FROM BIOMASS PYROLYSIS OILS
}

\author{
Xu Junming ${ }^{*}$, Jiang Jianchun and Lv Wei \\ Institute of Chemical Industry of Forest Products, CAF; National Engineering Laboratory for \\ Biomass Chemical Utilization; Key and Open Laboratory on Forest Chemical Engineering, \\ SFA, Nanjing 210042, China
}

(Received March 5, 2009; revised August 11, 2009)

\begin{abstract}
The possibility of using phenolic rich components (water insoluble fraction) from biomass pyrolysis oil as partial substitute of phenol in synthesis of high-ortho phenolic novolac under the catalyst of $\mathrm{HCl} / \mathrm{Zn}(\mathrm{AC})_{2}$ has been proved using differential scanning calorimetry (DSC) and Fourier transformed infrared spectroscopy (FT-IR). Synthesis of novolac resins with different concentration (10, 20, 30 and 40 wt \%) of phenolic rich components were investigated. Curing reaction of synthesized resins and DSC analysis showed that cure time of novolac was increased with the increasing amount of phenolic rich components and FT-IR analysis showed that the resins were high-ortho structure. It was determined that in order to obtain fast curing property, the concentration of phenolic rich components used in reaction should be below $10 \%$ (according to total amount of phenol).
\end{abstract}

KEY WORDS: Biomass, Pyrolysis, Phenol, Formaldehyde, Novolac, Preparation

\section{INTRODUCTION}

Phenol-formaldehyde or phenolic resins are typically cross-linkable polymeric resins made from phenol and aldehydes, usually pure phenol and formaldehyde. Novolac is one of the phenolic resins made under acidic conditions using excess phenol, the acid catalyzes the reaction of phenol and formaldehyde to form the cross-linkable polymeric resin. It is widely used for the formation of molded pieces and articles [1].

Because phenol is produced primarily from petroleum, its price and availability are linked to that of petroleum. Consequently, phenolic resins are relatively expensive. A number of attempts have thus been made in recent years to at least partially substitute the petroleum-based phenol in phenolic resins with inexpensive phenols derived from lignocellulosic wastes such as bark, sawdust, wood chips [2-5] and the like. Pyrolysis of biomass materials is known to produce a complex mixture of phenolic compounds which are derived primarily from the lignin contained in the feedstock. Therefore, such a complex mixture of phenolic compounds could be used as a substitute for the petroleum-based phenol in the synthesis of phenolic resins.

In this work, we have investigated the possibility of synthesis of high-ortho novolac resins (PPF) using water insoluble fractions from biomass pyrolysis oil, phenol and formaldehyde as starting materials through two step manner. Resins obtained have been characterized by several techniques.

\section{General}

\section{EXPERIMENTAL}

The fast pyrolysis bio-oil from biomass used in this study was the same as reported in literature $[6,7]$. IR spectra were obtained on a MAGNA-IR 550 spectrophotometer (USA). Gas chromatography-mass spectrometry (Agilent $6890 \mathrm{~N} / 5973 \mathrm{~N}$, USA) was conducted to analyze the composition of bio-oil. The separation was realized on a column of HP-5, $30 \mathrm{~m} \times 0.25 \mathrm{~mm} \times$ $0.25 \mu \mathrm{m}$.

*Corresponding author. E-mail: lang811023@163.com 
Cure time

The cure time of resins was determined (HG 5-1338-80, China). Each resin (1.0 g) with $10 \mathrm{wt}$ $\%$ hexamine was placed into the grooves at $150{ }^{\circ} \mathrm{C}$ and the time for the formation of gel was determined.

\section{Thermal analysis}

Thermal analysis was carried out with Pyris Diamond (Perkin Elmer, Germany) differential scanning calorimeter (DSC). A 5-10 mg sample was sealed in a medium pressure capsule pan and scanning temperature range from 25 to $280{ }^{\circ} \mathrm{C}$ was employed for thermal characterization. The sample crucibles were heated at $10^{\circ} \mathrm{C} \mathrm{min}^{-1}$.

\section{Experimental set up and procedure}

The reaction procedures are shown in Figure 1.

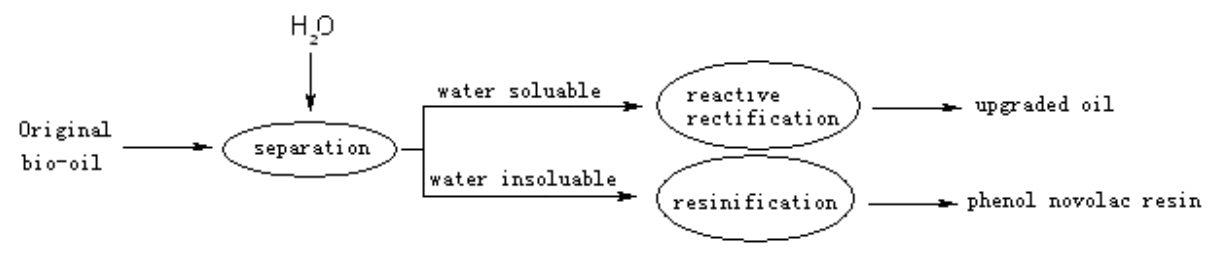

Figure 1. Scheme for utilization of pyrolysis oils.

Separation of original bio-oil was based on the fractionation of the bio-oil with water into water soluble and insoluble fractions. In a typical operation, $200 \mathrm{~mL}$ bio-oil $(232.0 \mathrm{~g})$ was added slowly as drops in $100 \mathrm{~g} \mathrm{H}_{2} \mathrm{O}$ with constant stirring, then fractionated to obtain watersoluble fraction (73.0 g) and water-insoluble fraction (82.4 g). Main components in original biooil [7] and water insoluable fractions are given in Table 1. The properties of original bio-oil are given in Table 2.

Table 1. Main components in original bio-oil [7] and water in soluble fractions.

\begin{tabular}{|l|l|l|l|}
\hline Original bio-oil & wt $\%$ & Composition & wt\% \\
\hline Composition & 7.69 & 3-Methyl phenol & 2.598 \\
\hline Formic acid & 2.31 & 2-Methoxy phenol & 7.644 \\
\hline Hydroxybutyric acid & 5.00 & 4-Ethyl phenol & 3.869 \\
\hline Toluene & 1.15 & 2-Methoxy-4-methyl phenol & 4.259 \\
\hline 3-Methyl benzoic acid & 1.22 & 3-Methyl-1,2-benzenediol & 1.602 \\
\hline 1,2-Benzenedicarboxylicacid & 1.42 & Hydroquinone & 0.928 \\
\hline 3-Methyl-2-cyclopentane-1-one & 2.15 & 4-Ethyl-2- methoxy-phenol & 2.823 \\
\hline 2,6-Dimethyl-4H-pyran-4-one & 1.00 & 4-Methyl-1,2-benzenediol & 2.473 \\
\hline 1-(4-Hydroxy-3-methoxy) acetophenone & 2.196 \\
\hline 2-Hydroxyl benzaldehyde & 1.85 & 2-Methoxy-4-vinylphenol & 4.251 \\
\hline 3,5-Dimethyl-4-hydroxyl benzaldehyde & 1.92 & Vanillin & 6.501 \\
\hline & & 2-Methoxy-4-(1-propenyl)-phenol & 5.930 \\
\hline
\end{tabular}

From Table 1, it was determined that there was formic acid in original bio-oil. So, it was possible to convert acid into ester and separate from bio-oil through reactive distillation. Bio-oil 
upgrading by means of ethyl ester production in reactive distillation was reported in our previous work [6]. It was also indicated that fraction quantity of phenolic compounds was increased in water insoluble fractions. Therefore, in this paper, we tried to use water insoluble fractions as a phenol substitute in novolac production.

Table 2. Main properties of original bio-oil.

\begin{tabular}{|l|c|}
\hline Properties & Original bio-oil \\
\hline $\mathrm{H}_{2} \mathrm{O}$ content $(\%)$ & 33.0 \\
\hline $\mathrm{pH}$ & 2.82 \\
\hline Calorific value $(\mathrm{kJ} / \mathrm{g})$ & 14.3 \\
\hline Density $\left(\mathrm{g} / \mathrm{cm}^{3}\right)$ & 1.16 \\
\hline Dynamic viscosity $\left(\mathrm{mm}^{2} / \mathrm{s}\right)^{\mathrm{a}}$ & 10.5 \\
\hline
\end{tabular}

${ }^{\text {a }}$ measured at a temperature of $30^{\circ} \mathrm{C}$.

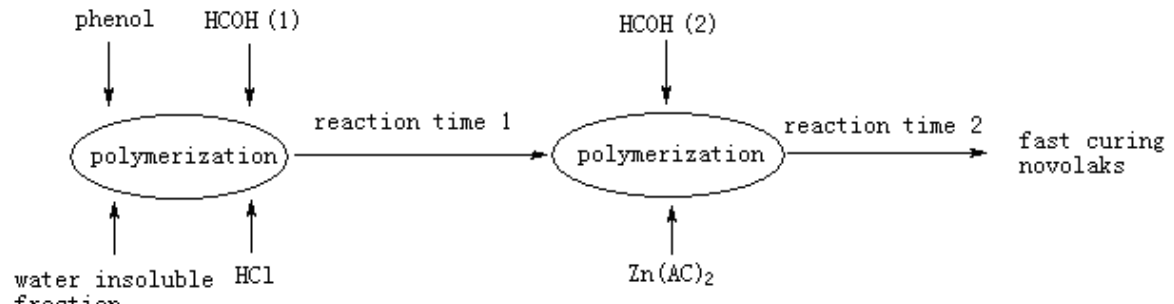

Figure 2. Scheme for synthesis of fast curing novolacs.

Figure 2 showed the process of synthesis of high-ortho novolacs (PPF) substitute by water insoluble fraction from biomass pyrolysis oils. Water insoluble fraction was added in several concentrations $(10,20,30$ and $40 \mathrm{wt} \%)$ in total amount of phenol used in synthesis of PPF. $\mathrm{F}_{1}$ (formaldehyde used in first step, $\mathrm{HCOH}(1)$ ): $\mathrm{F}_{2}$ (formaldehyde used in second step, $\mathrm{HCOH}(2)$ ) $=3: 2$. The reaction mixture was stirred and refluxed in the first step catalyzed by $\mathrm{HCl}$ and catalyzed by $\mathrm{Zn}(\mathrm{Ac})_{2}$ in the second step. After the completion of reaction, water was stripped off by distillation under vacuum at the end of the synthesis.

Novolac from pure phenol and formaldehyde (PF) was synthesized and characterized as reference. The synthesis process was the same as PPF.

\section{RESULTS AND DISCUSSION}

\section{Synthesis of novolac from pure phenol and formaldehyde $(P F)$}

Ortho-connection and contra-connection in novolac had a great influence on the cure time because the contra-position of phenol showed higher activity than ortho-position of phenol. By using $\mathrm{Zn}(\mathrm{Ac})_{2}$ as catalyst, it was possible to obtain high ortho novolac with short cure time compared with conventional novolacs because $\mathrm{Zn}(\mathrm{Ac})_{2}$ can promote the ortho-position connection in novolacs [8]. However, it took a long time to synthesis of high ortho novolac by using $\mathrm{Zn}(\mathrm{Ac})_{2}$ as catalyst. Moreover, the obtained novolac was in low soft point with poor yield. The catalytic activity of $\mathrm{Zn}(\mathrm{Ac})_{2}$ was not satisfied. On the other hand, using $\mathrm{HCl}$ as catalyst, the resin obtained was in high contra connection. The cure time of the novolac was long. 
In our experiment, in order to obtain a high yield of novolac with short cure time, we tried to use both of the catalyst to modify suitable ratio of ortho connection and contra connection in resin. It was found out that the soft point and cure time of novolac were all promoted by this two-step reaction. The results of novolac from pure phenol and formaldehyde (PF) are given in Table 3.

Table 3. Properties of novolac from pure phenol and formaldehyde.

\begin{tabular}{|l|c|c|c|c|}
\hline Catalyst & Reaction time $(\mathrm{h})$ & Yield $(\%)$ & Soft point $\left({ }^{\circ} \mathrm{C}\right)$ & Cure time (s) \\
\hline $\mathrm{HCl}$ & 2 & 91.9 & 96 & 105 \\
\hline $\mathrm{Zn}(\mathrm{Ac})_{2}$ & 7 & 67.3 & 45 & 65 \\
\hline $\mathrm{HCl} / \mathrm{Zn}(\mathrm{Ac})_{2}{ }^{a}$ & 3 & 90.4 & 92.5 & 43.5 \\
\hline
\end{tabular}

${ }^{\mathrm{a}}$ Reaction time of resin synthesized by $\mathrm{HCl} / \mathrm{Zn}(\mathrm{Ac})_{2}=$ reaction time $1(0.5 \mathrm{~h})+$ reaction time $2(2.5 \mathrm{~h})$.

\section{Synthesis of PPF}

Phenol used in novolac production was produced primarily from petroleum, its price and availability were linked to that of petroleum. Consequently, phenolic resins were relatively expensive. In previous GC-MS analysis, it was determined that the pyrolysis oils from biomass materials produce a complex mixture of phenolic compounds, especially richer in water insoluble fractions.

In this paper, in order to investigate the effect of water insoluble fraction on synthesis of fast curing novolac, we attempted to use phenol, formaldehyde and water insoluble fraction from phenolic-rich pyrolysis oils as starting materials through two step manner under the catalysis of $\mathrm{HCl}$ and $\mathrm{Zn}(\mathrm{Ac})_{2}$. The results of substitute ratio on the properties of novolac are given in Table 4.

Table 4. Effect of substitute ratio on novolac resins.

\begin{tabular}{|c|c|c|c|c|c|c|}
\hline $\begin{array}{c}\mathrm{m} \text { (phenol) : } \\
\mathrm{m} \text { (insoluble fraction) }\end{array}$ & $\begin{array}{c}\text { Reaction } \\
\text { time 1 }(\mathrm{h})\end{array}$ & $\begin{array}{c}\text { Reaction time 2 } \\
(\mathrm{h})\end{array}$ & $\begin{array}{c}\text { Catalyst, HCl/ } \\
\mathrm{Zn}(\mathrm{Ac})_{2}{ }^{\mathrm{a}}\end{array}$ & $\begin{array}{c}\text { Yield } \\
(\%)\end{array}$ & $\begin{array}{c}\text { Soft point } \\
\left({ }^{\circ} \mathrm{C}\right)\end{array}$ & $\begin{array}{c}\text { Cure time } \\
(\mathrm{s})\end{array}$ \\
\hline 0 & 0.5 & 2.5 & $0.1 \% / 1.5 \%$ & 90.3 & 92.0 & 45.5 \\
\hline $1: 9$ & 1.5 & 2.0 & $0.1 \% / 1.5 \%$ & 89.4 & 91.5 & 53.0 \\
\hline $2: 8$ & 2.0 & 3.0 & $0.2 \% / 1.5 \%$ & 83.6 & 91.0 & 84.5 \\
\hline $3: 7$ & 2.0 & 3.0 & $0.3 \% / 1.5 \%$ & 84.7 & 87.0 & 91 \\
\hline $4: 6$ & 1.5 & 3.0 & $0.4 \% / 1.5 \%$ & 86.5 & 92.5 & 101 \\
\hline
\end{tabular}

a mass ratio of $\mathrm{HCl}$ and $\mathrm{Zn}(\mathrm{Ac})_{2}$ to phenol.

Table 4 clearly indicated that with the increasing usage of insoluble fraction, the reaction time and catalyst used in reaction were also increased in order to obtain the novolac resin with suitable soft point. In previous GC-MS analysis, most of the components identified were oligomeric lignin-derived components. Compared with pure phenol, ortho-position and contraposition or both of position in these lignin derivatives was taken place by methyl, methoxy, propenyl, ketones, and aldehyde groups. It was difficult for them to react with formaldehyde because they did not provide enough amount of reacting position in molecular structure. Moreover, there were other components without phenolic structure. So these phenol derivatives used in synthesis of novolac resin were not in good reactivity. Therefore, it was shown in Table 4 that with increasing usage of insoluble fraction, the soft point of PPF was maintained by increasing the reaction time and amount of catalyst.

Figure 3 showed the ortho-connection and contra-connection in novolac. Ortho-connection of phenol and formaldehyde was at about $755 \mathrm{~cm}^{-1}$ and contra-connection was at about 850 
$\mathrm{cm}^{-1}$. It was indicated that the novolac catalyzed by $\mathrm{HCl} / \mathrm{Zn}(\mathrm{Ac})_{2}$ showed higher orthoconnection than the novolac catalyzed by $\mathrm{HCl}$ but lower ortho-connection than the novolac catalyzed by $\mathrm{Zn}(\mathrm{Ac})_{2}$. Figure 3 also showed the different substitute ratio on the effect of structure in obtained resins. It was showed that there is appearance of new bands at about 1700 $\mathrm{cm}^{-1}$ in $\mathrm{d}$, e, $\mathrm{f}$ and $\mathrm{g}$. These bands must be attributed to the biomass pyrolysis oil presence in resins because they are not present in reference resin spectra ( $a, b$ and $c)$. It was also indicated that using water insoluble fraction from biomass pyrolysis oil as phenol substitute, the obtained novolac still remain its high ortho-connection. Other characteristic vibrational modes are observed at $3400 \mathrm{~cm}^{-1}$ (OH stretching, 2850-2980 $\mathrm{cm}^{-1}$ (CH stretching, aliphatic), and $1310 \mathrm{~cm}^{-1}$ (C-O stretching).

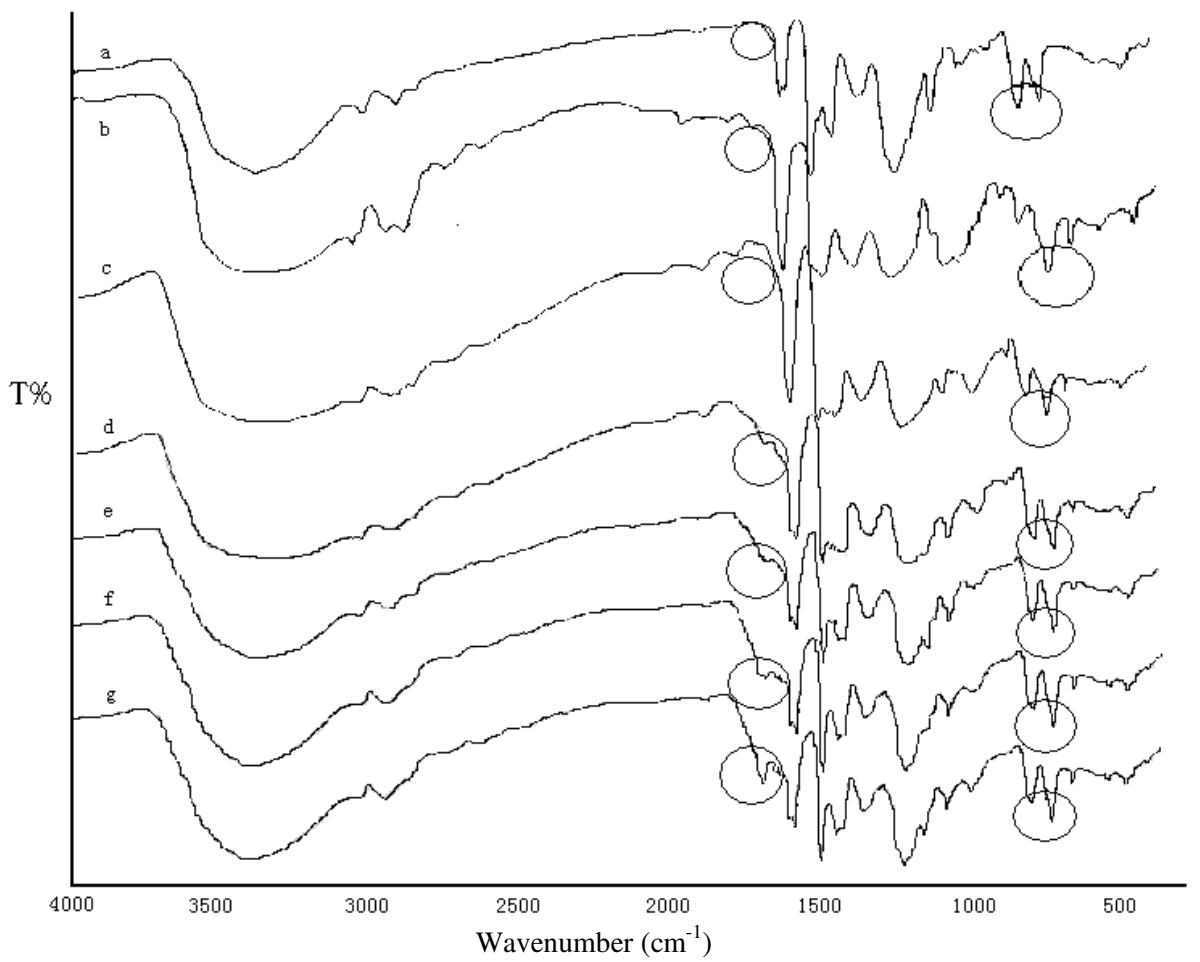

Figure 3. IR spectra of novolacs (a, catalyst: $\mathrm{HCl} ; \mathrm{b}$, catalyst: $\mathrm{Zn}(\mathrm{Ac})_{2}$; c, catalyst: $\left.\mathrm{HCl} / \mathrm{Zn}(\mathrm{Ac})_{2}\right)$ and novolacs in different substitute ratio (d: $10 \%$; e: $20 \%$; f: $30 \%$; g: $40 \%$ ).

Figure 4 showed the thermograms obtained from different catalyst. It was indicated that the cure reaction of resin catalyzed by $\mathrm{HCl} / \mathrm{Zn}(\mathrm{Ac})_{2}$ occur at lower temperature than the one obtain by strong acid $(\mathrm{HCl})$. This conclusion was in good agreement with the result of IR spectra in Figure 3. It was also showed that onset temperature of novolacs was increased with the increasing amount of water insoluble fraction used in synthesis of resins. But the cure reaction start at about $60-70{ }^{\circ} \mathrm{C}$, it must be attributed to the condensation reaction of water insoluble fraction [9] presence in resins because the biomass pyrolysis oil is not a product of thermodynamic equilibrium [9]. It nearly involves all species of oxygenated organics, such as aldehydes, ketones, phenols, carboxylic acids and alcohols with good reactivity. Therefore, the 
chemical composition of the bio-oil tends to change toward thermodynamic equilibrium and release the heat during thermo-process.

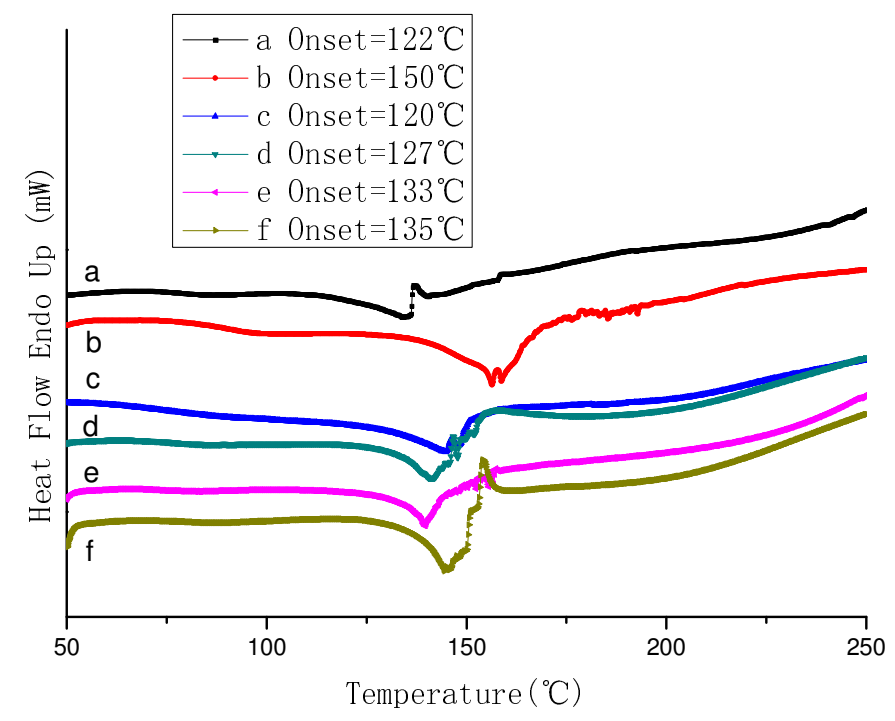

Figure 4. DSC thermograms of novolacs (a catalyst: $\mathrm{HCl} / \mathrm{Zn}(\mathrm{AC})_{2}$ ); b catalyst: $\mathrm{HCl}$ ) and novolacs in different substitute ratio (c: $10 \%$; d: $20 \%$; e: $30 \%$; f: $40 \%$ ) with 10 wt \% hexamine.

\section{CONCLUSIONS}

The possibility of using phenolic rich components (water insoluble fraction) from biomass pyrolysis oil as partial substitute of phenol in synthesis of phenolic novolac was investigated in this paper. It was determined that the novolac catalyzed by $\mathrm{HCl} / \mathrm{Zn}(\mathrm{AC})_{2}$ gave high-ortho connection in molecular structure. The curing properties of novolac were proved using differential scanning calorimetry (DSC). It was found that the cure reactivity of novolac was decreased with the increasing amount of phenolic rich components. In our future work, we aim to extract phenol rich compounds from water insoluble fraction to use as phenol substitute.

\section{AKNOWLEDGEMENTS}

The authors would like to thank the National Natural Science Foundation of China (30700634) and Commonweal research of CAF (200904008, CAFINT 2008C03) for the financial support during this investigation.

\section{REFERENCES}

1. Christian, R.; Xiao, L.; Hooshang, P. US 6143856, 2000, 11; Chem. Abstr. 2000, 133, 137074.

2. Kim, S.; Lee, Y.K.; Kim, H.J.; Lee, H.H. J. Adhes. Sci. Technol. 2003, 17, 1863.

3. Regi, G.; Barry, F.; Robert, G. US 6326461, 2001, 12; Chem. Abstr. 2001, 134, 163824. 
4. Pena, C.; Larranaga, M.; Gabilondo, N.; Tejado, A. Echeverria, J.M.; Mondragon I. J. Applied Polym. Sci. 2006, 100, 4412.

5. Chiho, S.; Yoshiaki, N.; Tadamasa, N. Nettowaku Porima 2006, 27, 218.

6. Xu, J.M.; Jiang, J.C.; Sun, Y.J.; Lu Y.J. Biomass and Bioenergy 2008, 32, 1056.

7. Zheng, J.L.; Zhu, X.F.; Guo, Q.X. Waste Manage. 2006, 26, 1430.

8. Bender, H.L.; Farnham, A.G.; Guyer, J.W.; Apel, F.N.; Gibb, T.B. Ind. Eng. Chem. 1952, $44,1619$.

9. Zhang, Q.; Chang, J.; Wang, T.J.; Xu, Y. Energy Convers. Manage. 2007, 48, 87. 